UCRL-JC-122134

PREPRINT

\title{
LLNL Pure Positron Plasma Program
}

J. H. Hartley, B. R. Beck, T. E. Cowan, J. Fajans, R. Gopalan

R. H. Howell, J. L. McDonald, R. R. Rohatgi

This paper was prepared for submittal to the

\section{RECEIVED \\ NOV 171995 \\ OS TI}

American Institute of Physics

Non-Neutral Plasma Physics II

Berkeley, CA

July 21-23, 1994

September 27, 1995

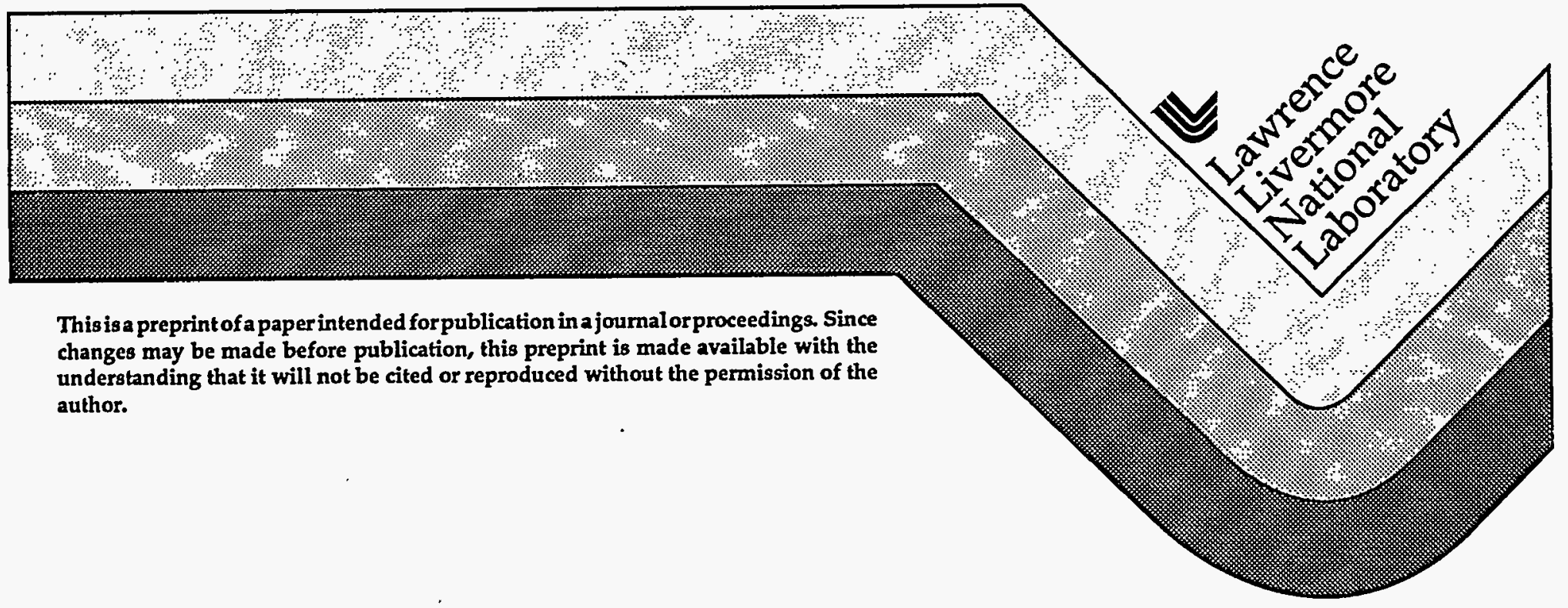




\section{DISCLAIMER}

This document was prepared as an account of work sponsored by an agency of the United States Government. Neither the United States Government nor the University of California nor any of their employees, makes any warranty, express or implied, or assumes anylegal liability or responsibility for the accuracy, completeness, orusefulness of any information, apparatus, product, or process disclosed, or represents that its use wouldnot infringe privately owned rights. Reference herein to any specificcommercial products, process, or service by trade name, trademark, manufacturer, or otherwise, does not necessarily constitute or imply its endorsement, recommendation, or favoring by the United States Government or the University of Colifornia. The views and opinions of authors expressed herein do not pecessarily state or reflect those of the United States Government or the University of California, and shall not be used for advertising or product endorsement purposes. 


\section{DISCLAIMIER}

Portions of this document may be illegible in electronic image products. Images are produced from the best available original document. 


\title{
LLNL Pure Positron Plasma Program
}

\author{
J.H. Hanleys, B.R. Beckt, T.E. Cowant, J. Fajansł, R. Gopalanł. \\ R.H. Howellt, J.L. McDonaldi, and R.R. Rohatgit \\ IPhysies Deparment and SU.C. Davis Department of Applied Scicnce, Lewrence Livermare \\ Notianal Laboranny, Livemore, CA ges51 \\ \$Physies Departmen, Universiny of Californis, Berteley, CA, 94720
}

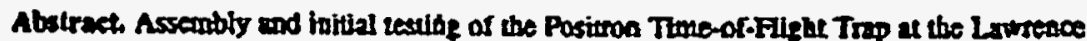

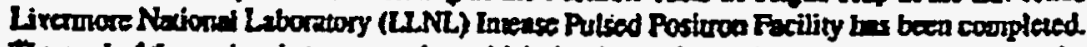

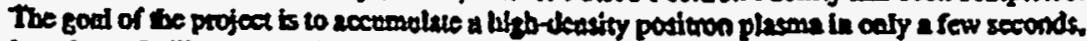
in octer to focilitute study then may require destructive disgrostict. To date dencities of at least 6a $10^{6}$ positrons per $\mathrm{cm}^{3}$ have been achieved.
\end{abstract}

\section{TRAP DESIGN}

The LLNL pure plasma trap has an unusual contiguration for a non-neutral plasma device, which was driven by its intended use 23 inigh-deasity posiuron gas larget for particle physics experiments (1). The positron tre consists of a $76 \mathrm{~cm}$ long cylindrical-electrode Penning-Malmberg tre in a high-uniformity solenoid capable of producing a $62 \mathrm{kG}$ axial magnetic field. The apparatus is siluated on the positron beam line of the LLNL $100 \mathrm{MLV}$ electron Linac.

At the time of the design, the conventional wisdom in non-neutral taps was that aximuthal asymmetries of the field and clectrodes were a major limiting factor to the plasms confraermeat time (2). For this reason. greal care was taken wo ensure that the solcnoid field was very uniform. and that the electrodes were aligned with great precision. The measured field surength vartes by less than $0.1 \%$ axially over the length of the trap, and $-20 \mathrm{ppm}$ peak-10-peak azimurhally at the electrode radius of $1 \mathrm{~cm}$ (Fig. 1). The size and radial dependence of the asymmetries in the field can be accounted for by a horizontal $0.125 \mathrm{~mm}$ bow in the $1 \mathrm{~m}$ long coil, resulting in toroidal fiald with a radius of curvature of $1 \mathrm{~km}$.

The electrodes are golu-plated copper cylinders aligned in a ceramic V-block cridle. All components are machined to 2.5 um tolerance over the length of the trap. The trap stucture is siusaled in a copper bore whose temperature can be varied from $300 \mathrm{~K}$ to $4.2 \mathrm{~K}$.

The primary plasma diagnostic consists of a micto-channel plate (MCP) in front of a phosphor screen. imaged hy a CCD camcra. Camera images are capurred on a VAX Workstation. 


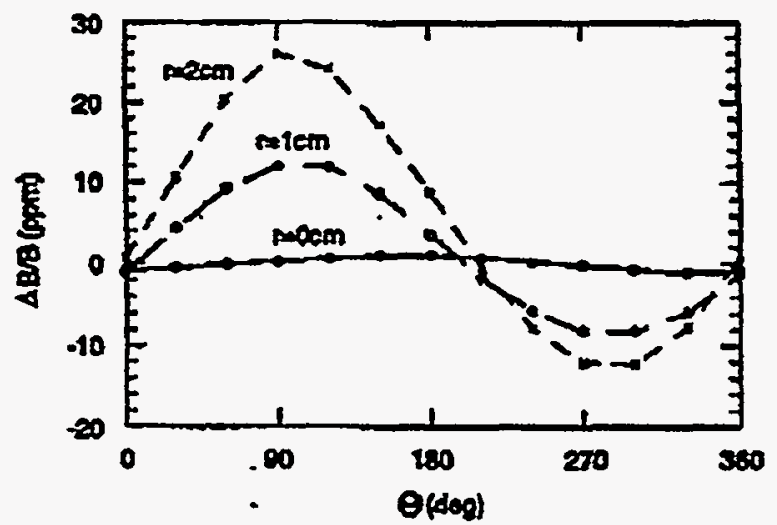

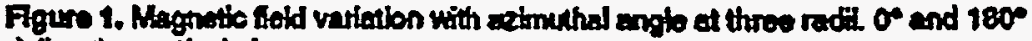
dofite the vortieal plene.

\section{OPRRATION WITH ELECTRON PLASMAS}

Preliminary testing of the trap uritized electrons from a spiral flament as the plesms particles. The trap region was $6 \mathrm{~cm}$ long, with B-30 kG and T=77 $\mathrm{K}$. Fasma density measurements were made by dumping the plasua from the trap onto a phosphor screen. The modial density protlie was determined from the image intemsity and a capacitive pick-off of the total charge on the zcreen.

At the time of oft initial measurements, surmarized in Figures 2 and 3, the CCD camem imaging syatem was not yet operational, co humen eyes and a raler were used to meassme the diameres of the plasma. Work done at UC San Diego (3) and UC Beskeley (4), and the qualitative appearance of the phosphor image, spggested that assuming fiat proffle would be a reasonable approximation and that the calcalared average density was adequate to characterizo the plasma expansion.

The plasma underwent an carly stage of rapid transport, followed by a much slower expansion. This was consistent with the behaylor of other non-neutral plasma devicer, and suggested a quick evolution of the redial proffle to an equilibrinm flat distribution. The dats wis fit as two exponentials, and the $t=0$ equilibrium density wes defined to be the intercept of the second. slower exponential with the $y$ axis. Confinement time was deftned as the time if took for the average density to drop to one-half of the equilibrium density.

With the bore as $500 m$ semperamre, confinement times were on tho order of ten seconds. With the bore cooied to $77 \mathrm{~K}$, fifetimes improved to as much as several thousand seconds. This factot of 100 difference is presumed to result from the improvement in vecuum pressure doe to cryopumping. Pressure measured well ousside the cryopumping region improved from $2 \times 10^{-9}$ to $2 \times 10^{-10}$ Tor with cooling and the improvement was likely much greater in the trap region.

Earlier work (5) has soggested that the lifetime scaling should follow:

$$
\tau_{m}=\frac{B^{2}}{L^{2}} \cdot \frac{1}{P} \cdot \frac{f(r)}{n^{a}}
$$




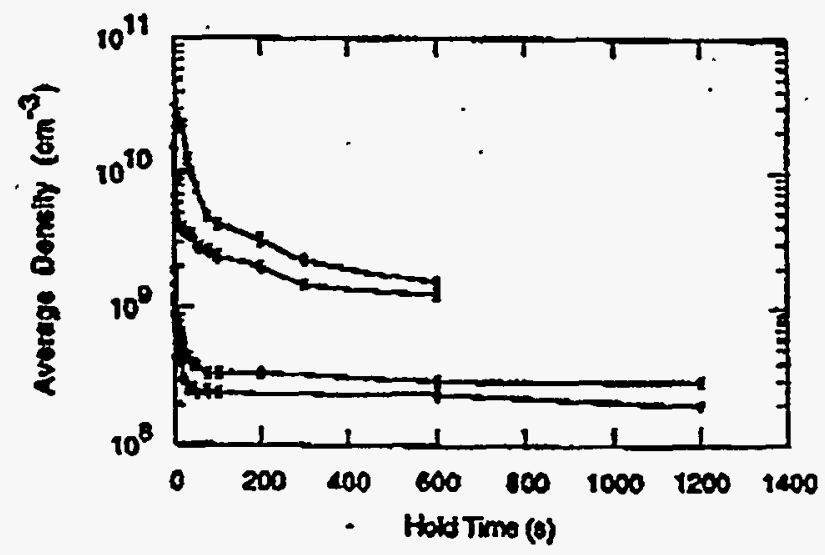

Flgura 2. Eloctron average donsity as a function of hold thne. (L=6 cm. B=30 kG, $T=77$ n)

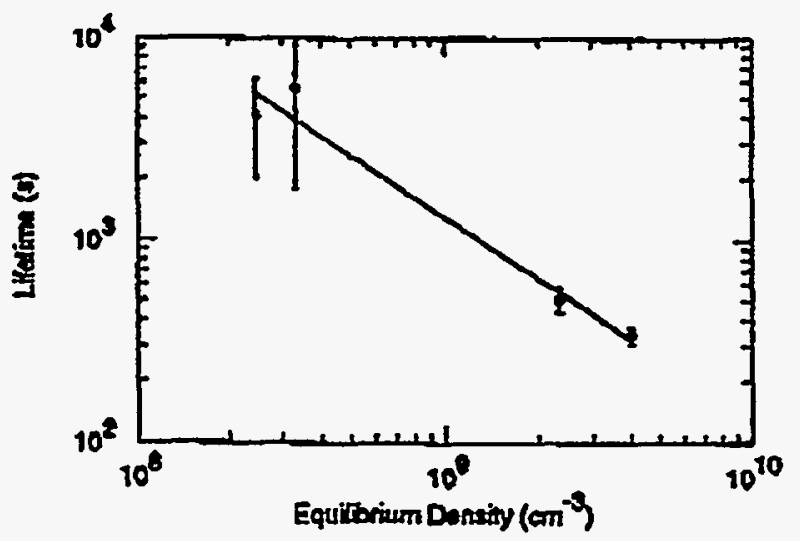

Figure 3. Eloctron ptatema lietime as a function of equithitum densthy, deferminod from" data in Fig. 2 sor hold times greader than $100 \mathrm{~s}$

where $B$ is the magnelic field. $L$ is plesma length. $P$ is neutral pressure. $n$ is plasma density, and $f$ is an undetermined function of plasma temperalure. $A$ fit to the LLNL data (Fig. 3) indicatcs a value of ast. Interpolating over several orders of magnitude in density and radius between UCSD dats (S) and these preliminary LLNL data suggests a-1.5. The CCD camera diagnostic is now fully on-line. and work is underway to further refine the trapping characieristics and scaling laws of this device.

\section{POSITRON BEAM AND PULSED INJECTION}

Positrons are injected into the trap from the LLNL Linac intense pulsed positron beam. (6) The positron bcam is produced from the photon-electron-positron shower 


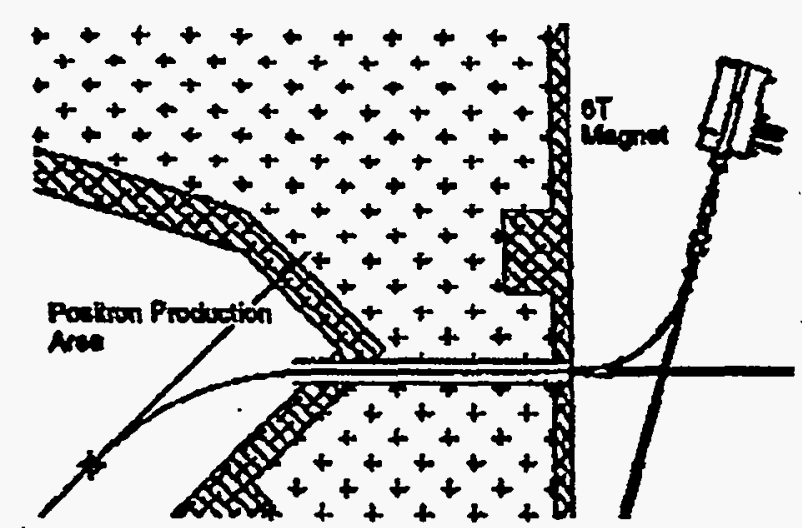

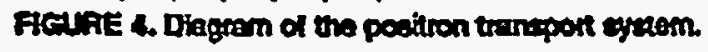

generated by the $100 \mathrm{MeV}$ electron beam in 2 tungeten converter targel. High energy positrons are themalized in a sel of tungsten vanes, which have a negative work function for pasitrons, so thase that diffuse to the vane surfaces are ejected with $1-2 \mathrm{eV}$. To preserve the 20 ns pulse width during transport through the solenoidal guide field to the trap (Fig. 4), the positrons are accelerated electrostaticly to $-6 \mathrm{kV}$. The position livx, determined from the annibilation radiation at a beam stop just upstream of the imp, is $3 \times 10^{6} \mathrm{et} /$ pulse. At the maximum Linac repetition rate of 1440 palses/s, the beam intensity is $4.4 \times 10^{\circ} \mathrm{et} / \mathrm{s}$.

The trapping scheme for accumulaing positrons makes use of the palsed nature of the postron berm. A $1000 \mathrm{~A}$ tungsten remoderation foil at the front of the trap thermalizes the positons, with $-20 \%$ efficiency, greatly enhancing the phase-space brightness of the beam by removing the large axill energy spresd resulting from injection into the high magnetic field. The $1-2 \mathrm{eV}$ positrons are then more essily

captured in the trap. Trapping proceeds in two phases, the first by simpie TOF (ime-of-flight) capture, followed at higher positron densities by collisional cooling into the exinl well In the first phase, the remoderation foil which is used as an electrostatic end cap, is dropped to ground potential for a time $\tau_{p} z \tau_{p}$, where $\tau_{p}$ is the widih of the positron pulse. The posituons drifi fato the trap ind spretd evenly throughout the tripping region before the next palce arrives. The frection of trapped particles lost when a new pulse is injected is $\tau, t_{n}$ where $\tau_{c}$ is the round-urip unvel ime of positrons in the trap. The number of pulses trapped in this phese then asymptotically approsches $\tau_{\mathrm{f}} \boldsymbol{\tau}_{\mathrm{g}}$, at which point posituous are lost at the same rate at which they are infected.

The second phase of trapping occurs when the denstity of particles in the trap is high enough for collisions to equilibrate the transverse and longitudinn tempercures beforo the next polse arives ( $)$. The trep is held al a negative bias, so as longimdinal energy is rcatered into the transverse degrees of freedom the positrons cool into une axial potendal well. Cyclotron rediation cools the transverse energy in less than a second. Once the positurns are in the potential well they can no longer cocape when the front barries is lowered. The trensition to this second phrese of trapping can be clearly seen in numerical simolutions. For example, Figure 5 shows positron accomolation for the conditions in our first positron injection 


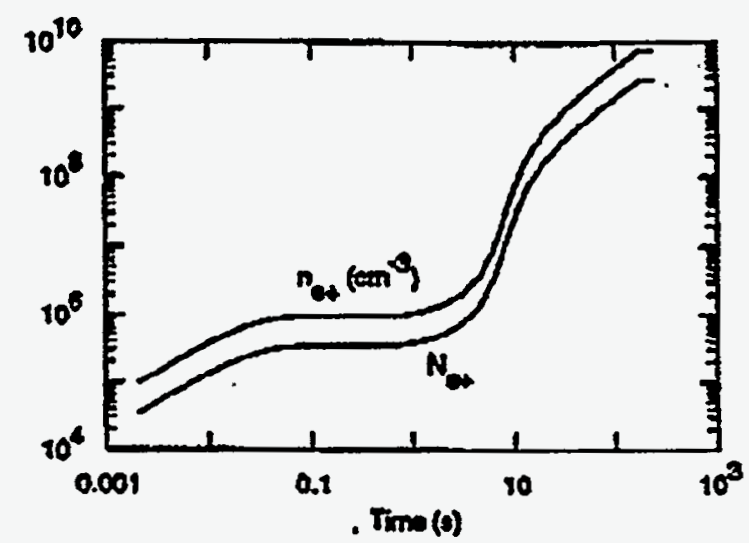

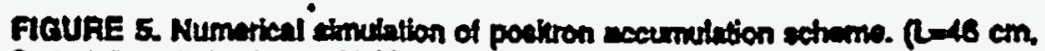
B.30 kG, wed dopth a $60 \mathrm{~V}$. Linac rep, talo a $480 \mathrm{ppa}$ )

experiments, described below. Under ideal conditions of injection and remoderation. $-9 \times 10^{7}$ positrons could be trapped per second.

\section{FIRST RESULTS OF POSITRON INJECTION}

The two major techoieal difficulties encountered in the first experiment were transport into the high-field region of the trap and remoderation of the positrons. As the positrons passed from the $150 \mathrm{G}$ gnide field into the $30 \mathrm{kO}$ freld used in the experiments presented here, magnetic mitroring gave an seceptance angle of less than five degrees. Irregolerities in the guide field provided a transverse impulse to the positrons, resulting in a "spinning up" of the beam and consequent mirroring of the positronk. Refined techniques for operating the transport magnets improved transtristion efficiency from an initial value of 1\% to grearer than 35\%.

The unannealed tungaten foil used in the initial experiment gave only a $0.8 \%$ remoderation efficiency, instead of the expected $20 \%$, when cooled to $77 \mathrm{~K}$ with the rest of the trap. Cryetal defects in an unannesled foil inhibit positron difmusion to the surface Cryopumping of impurities on the foil wonld inhibit re-emission. A secent experiment with an annealed foil at $300 \mathrm{~K}$ has improved performance to 5 . $6 \%$ remoderation. Cooling the bore with the anncaled remoderation foil in plsce will show whether cryopumping is actually a problem requiriag redesign of the IEmoderaton stage.

These improvements resulted in $3.5 \times 10^{\text {t }}$ remoderared positrons injected into the trap per pulse. The round-rip flight time onss 240 is in this trap configuration. With an injection fate width of 25 ns, the TOF capiure limil wis about $3.5 \times 10^{5}$ positrons, achieved in a small fraction of a second. The actual accumulation of positrons as a function of hold lime is shown in Figure 6. The fact thit positrons continued to accumulate for up $1020 \mathrm{~s}$ indicates that particle cooling into the well was cocurring. The time distribution of the charge signal as the trap was dumped indicates a significant accumolation of positsons near the bottom of the potemial 


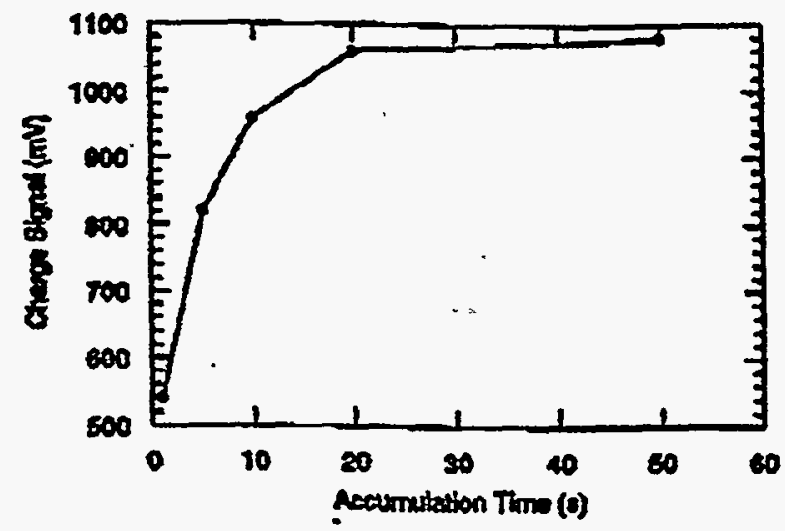

Figur a. Charge durp sibial on phophor as a function of eccumulition tim.

well. Both the accunulation nate and the miximum density schieved scaled linearly with the repetition rate of the positron beam.

Calibration of the total number of positrons with the observed charge signal was complicated by samuration of the MCP. The relatively low tepetinion rate of ons charge dump per 20 s made sutistical counting from the annifilation gamma-ray signal alko difficult. Three attempls at indirect calibration were made, uxing electron pirsma diocotron measurements, the annilillation signal of single positron polses. and the signal from a change-seasitive pre-amp atteched to the MCP with no voltage across the piate. Different calibrations give resules renging from $1.8 \times 106$ to $2 \times 10^{7}$ positrons irapped. Direct measurement of the number of trapped purticles will be wade in the next $\mathrm{rm}$ by looking at the diocotron frequency of ibe positron colvmin. The large number of positrons captured also allows use of the MCP at lower gain, which should reduce the problem of charge saturation.

An image of the dnmped positron plasms is shown in Figure 7. Tho measured FWtiM radius was $0.45 \mathrm{~mm}$. The trapping region was $46 \mathrm{~cm}$ loug, whieh gave a volume of approximarely $0.29 \mathrm{~cm}^{3}$, and 2 density of al lest $6 \times 10^{6} \mathrm{~cm}^{-3}$ and possibly as high $2{ }^{2} 6 \times 10^{7} \mathrm{~cm}^{-3}$ :-

A comparison of the data of Figure 6 and calculations of Figure 5 reveals several important resultes regarding positron accumulation and confinemeat Initilly, the trap was fluling too quickty to be acconnled for by positron collisions alone. For eximple, the calculated density at $1 \mathrm{~s}$ is $106 \mathrm{~cm}^{-3}$, but the actull sccumulation was at least three times that value. The accumulation should coptinue finearly throughout this range, bat the results show saturation, while $C C D$ images indieated no radial uransport. This implies a large effect from collisions with neutral particles, enhancing earty collisional cooling toto the well and causing positron loss the to antilhilation or positroniom formation on a time scale of a fert ceconds. This dath is consistent with the early results of Surto of al. (8). Experiments to inoprove

\footnotetext{
- An abotract for a poster sexion at the ammunl meeting of the AFS Division of PIam Fhydics mistaken'y soggested that design-goal densities of $1010 \mathrm{~cm}^{3}$ hed actunlly been ochilered. We apologine for the error.
} 


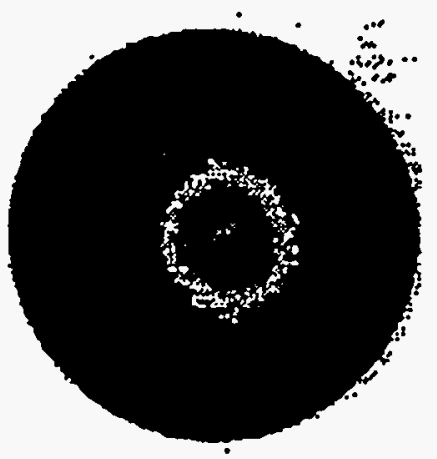

Flgure 7. CCD Image of positron column. FHath redines is 0.45 mm

confinement by cooling the trap are in preparation. If surface contamination of the remoderation foil proves not to he a limiting factor, we expect to achieve significantly higher densities in the near future.

\section{ACKNOWLEDGMENTS}

We wish to acknowledge the invaluable assistance of $\mathbf{W}$. Palterson and $H$. Koberlt in the development of the experiment and the operation of the Linze. This work wis fanded by the LLNL Laboratory Directed Researeh and Development program and the LLNL Plasma Physics Research Institute. Work was performed under the auspices of the U.S. Deparment of Energy by Lawrence Livermore National Laboratory under contract No. W-740S-ENG-48.

\section{REFERENCES}

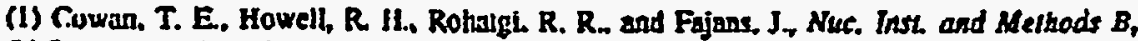
56-7. 599-603 (1991).

(2) Driscoll. C. F., and Malmborg, J, I1., Phys, Rev, Ler., 50, 167-170 (1983).

(3) Malmherg, J. H., and Drisonll. C. F.. Phus, Rev. Let., M. 654-657 (1980).

(4) Peurmug. A. I. and Fajans. I. Phys Fluids B. 1. 2073-2084 (1989).

(S) Coss, A. contribation, this conference.

(6) IInwell R. H. Rowenherg, I. J.s and Fuss, MJ. Applied Physics A, 43, 247-25s (1987).

(T) Beck. B. R. Fajane J. and Malmberg, J. KL. Phys, Rev. Let. 68, 317-320 (1992).

(8) Surko, C.M. Leventhal. M. Passtues, $\Lambda$. and Wysocki. FI. "A Positon Plesma in the Laboratory - How and Why", Pracredings of the ONR Confereace on Nont-Neutral Plasmar. 1988. P. 18:-200. 